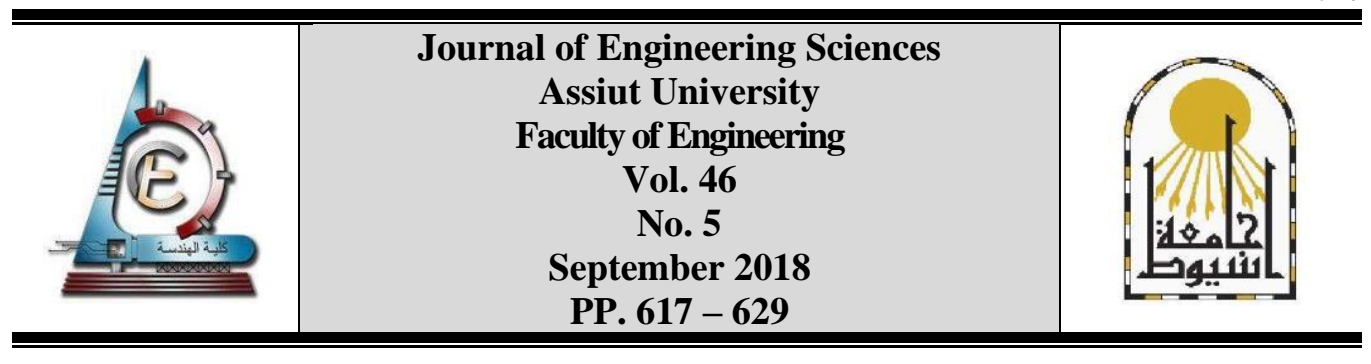

\title{
THE DEGREE OF URBAN PATTERNS COMPACTNESS AS A PASSIVE COOLING STRATEGY IN HOT DESERT CLIMATE "WADI KARKAR VILLAGES - ASWAN AS A CASE STUDY"
}

\author{
Mohamed Hssan Hassan Abdelhafez \\ Department of Architecture, Faculty of Engineering, Aswan University.
}

Received 3June 2018; Accepted 10June 2018

\begin{abstract}
Pedestrian thermal comfort is related to the urban patterns generated from a specific urban planning methodology. It is noteworthy that urban planning process in Egypt does not consider passive urban design strategies to help reduce heat stresses, although there are historical examples of environmental architecture such as the Nubian architecture which considered one of the most famous examples of the desert architecture, where interacted with the surrounding environment. Therefore, this study investigates the best possible ratio for urban compactness as a passive cooling strategy. Moreover, it definesthe relationship between the compactness degree, air temperature, and air velocity, also the researchproposes the appropriate conditions for improving the pedestrian wind comfort. The numerical simulations were conducted, using the Autodesk CFD 2016 software. This research suggests some modifications for a variety of ratios in different orientations. The results show that the ratio $1: 1.5$ in the North-South orientation records the best value of the temperature and the air velocity. The results of the correlation indicate that the higher the air velocity the lower the air temperature and vice versa. In addition, the air velocity in most of the cases is suitable for long time outdoor sitting in different orientations.
\end{abstract}

Keywords: Pedestrian thermal comfort, Pedestrian wind comfort, Urban compactness, Passive cooling strategy, Nubian architecture.

\section{Introduction}

The environment consists of the natural and built environments, and the environmental design aims to achieve thermal, aural, visual and physical comfort together with psychological comfort for indoor or outdoor conditions. Concerning the thermal comfort in outdoor spaces, it has been argued that urban patterns have a significant effect on the climatic conditions. Due to spatial fabric distribution that influences radiant exchange as well as the wind within the canopy layer and outlines the importance of initially defining the pattern type by which a master plan design begins [1].

Therefore, an understanding of different patterns effect is necessary. In this context, different comfort effects of various forms were demonstrated, and the results indicated that the bigger the degree of compactness, the more comfortable was [2]. Also, the 
compactness increases sustainability regarding short travels within neighborhood parts, [3] and closing to pedestrian comfort [4].

On the other hand, over the centuries, Egypt has witnessed a significant period of many ancient civilizations such as; Pharaonic, Greek, Roman and Islamic. These historical periods helped to create ancient Egypt.Farther south, specifically in Aswan, where it is Egypt's southern gate to Africa.It has contained the Nubian regions, which were a mixture of those civilizations and interacted with the surrounding environment [5].

Nubia was the area between the first and third cataracts of the Nile south of Egypt. Due to the construction of the High Dam in 1964, Nubia was flooded by the lake water created behind the dam. As a result, the Nubians, who had lived for hundreds of years in vernacular villages and dwellings, were relocated to planned communities. These communities were different from the vernacular ones of old Nubia [6].

The Nubian architecture is one of the most famous examples of the desert architecture, where the natural environment played a definite role in the formation of this architecture. Thus, the elements of the climate greatly influenced the characteristics of the traditional Nubian village, and this influence was evident in the planning of the village (as shown in Fig. 1), where the availability of shadows by using the dense pattern in the planning which reduced the exposure of the facades to direct solar radiation [7].
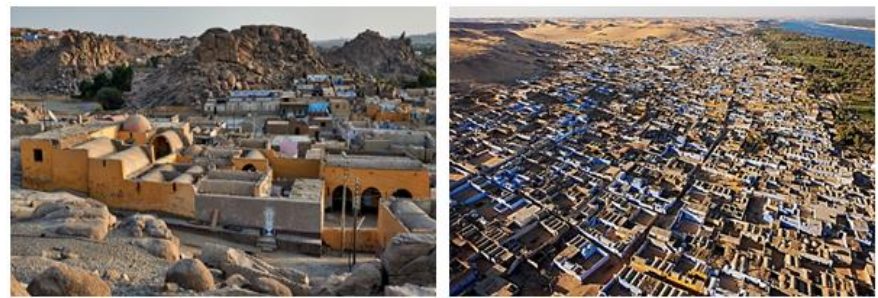

Fig. 1. The influence of the climate on the vernacular Nubian architecture ${ }^{[7]}$

Also, Nubians depend on subsidiary and winding roads to protect the residential area of hot, dusty wind and reduce the temperature, also, to increase the amount of shading on the road by increasing the ratio between the widths of the road to the height of the buildings [8].

The issue of resettling the Nubians to their ancient lands around the Lake Nasser has become a public concern. Therefore, the Egyptian government has implemented the project of rehabilitation and resettlement of the Nubians in WadiKarkar in Aswan city, which is about 3.5 kilometers away from Lake Nasser [9].

This project considered the socio-economic dimensions of the Nubians but failed to create comfortable thermal conditions for the living of people in these villages as shown in (Fig. 2), as in the traditional Nubian villages [10].
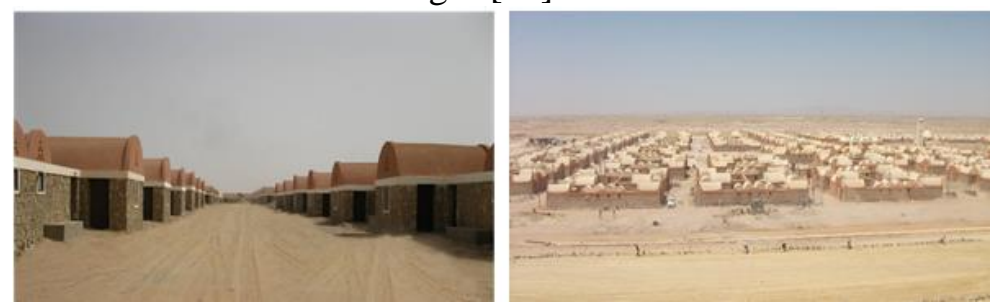

Fig. 2. The negligence of the climatic dimensions in modern Nubian villages (photographed by the researcher) 
Mohamed Hssan Hassan Abdelhafez, The degree of urban patterns compactness as a passive ...

The previous review indicates the difference between the vernacular and the modern Nubia and shows the need for more focus on measuring the effect of compact patterns on the improving the environmental comfort and the quality of life as well.

So, This research is an attempt to revive the urban planning solutions that were provided by the vernacular Nubian architecture according to the degree of compactness to achieve the thermal comfort in outdoor spaces. The study focuseson the passive cooling strategy of shading and preservation of natural resources through natural ventilation and thermal efficiency of the vernacular techniques.

\section{Objectives and methodology}

The main objective of this study is to find satisfactory urban forms that give minimal heat stress, which may contribute to improving urban planning techniques in hot desert climatic zones. Also,the study aims to determine the best possible ratio for urban compactness as a passive cooling strategy. Moreover, define a relationship between the pattern compactness degree, air temperature, and air velocity. Another purpose of this study is to propose suitable conditions to improve the pedestrian wind comfort.

To achieve the objectives of the research, the field measurements were conducted to clarify the current thermal conditions in two different Nubian sites, which in turndetermine the difference between the vernacular and modern planning of the Nubian villages.

To support the planning decision by giving an advantage for one of the suggestions, an assessment of the outdoor thermal performance was conducted. Simulation is the preferred method due to the large area of the case study as well as the nonrepresentation for the whole site if measurements took place. The numerical simulations were performed, using AutoDesk CFD 2016 software, The simulation software was validated with field measurements, to obtain the accuracy of the program, and then verify the reliability of the results.

A section of a neighborhood in one of the modern villages of Wadi Karkar was selected to be the urban context for this study, this section consists of four adjacent units clusters with the same designas shown in (Fig. 3).

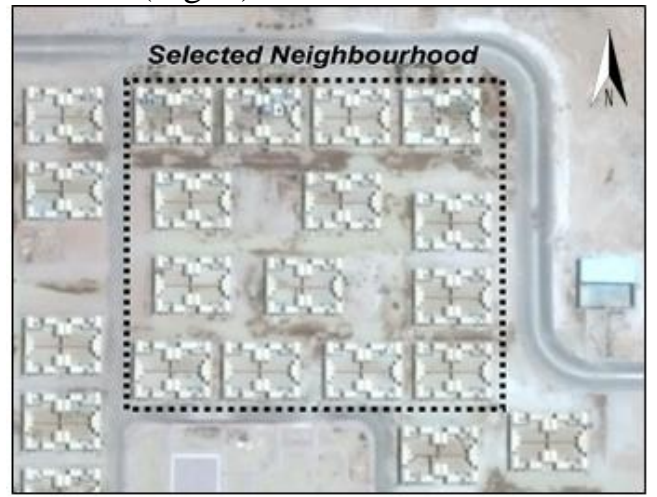

Fig. 3. The selectedneighborhood for the study

To investigate the effect of compact planning, the research suggests some modifications for a variety of ratios between the width of the streets and the height of the buildings. The modifications include a comparison of four different orientations of the streets: NorthSouth, East-West, Northeast-Southwest, and Northwest-Southeast as shown in (Fig. 4). 

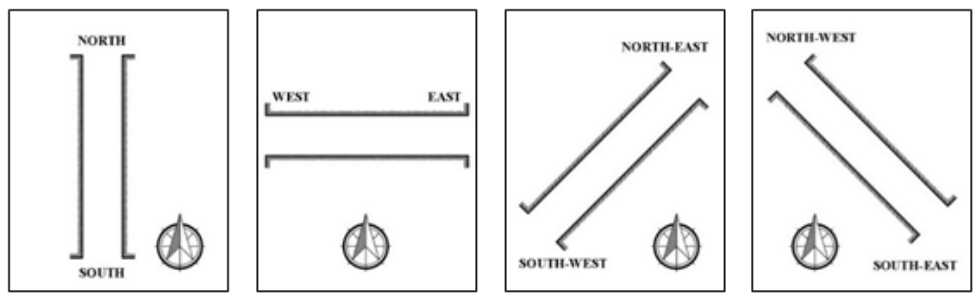

Fig. 4. The selected four orientations

The streets width ratio has been adjusted to the height of the buildings with each orientation as shown in (Fig. 5).
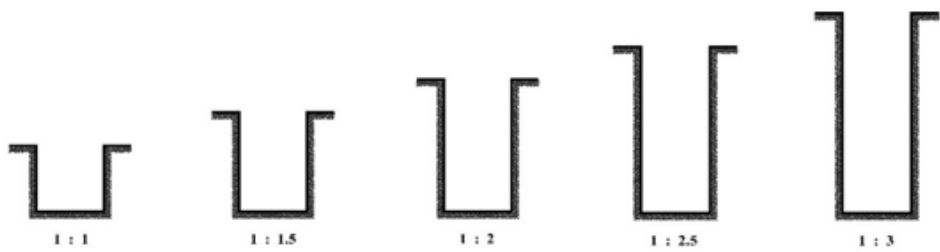

Fig. 5. The streets width ratio used in the study

Some recent studies for a limited range of urban spaces indicate that the pedestrians feel discomfort when strong air movement occurs frequently, according to the case study of each research and meteorological of each zone [11].Where Bottema has performed a comprehensive study of the different safety and comfort criteria used through the recent decades. The abovementioned study has discussed 15 different categories of pedestrian comfort based on the gust wind speed and its duration. This study shows that both gust speed and its occurrence time period are important factors for analyzing pedestrian comfort during severe wind actions [12].

A simple rule of thumb has been provided by Wise and Pendwarden, which based on mean speeds (V) assuming that the $\mathrm{V}=5 \mathrm{~m} / \mathrm{s}$ will be theonset of discomfort. When $\mathrm{V}=10 \mathrm{~m} / \mathrm{s}$ it will be definitely unpleasant. And if $\mathrm{V}=20 \mathrm{~m} / \mathrm{s}$ it is considered dangerous. Therefore, conditions for pedestrians are considered acceptable if $\mathrm{V}>5 \mathrm{~m} / \mathrm{s}$ less than $20 \%$ of the time [13].

The Dutch wind nuisance standard NEN 8100 has recently been proposed. In the NEN 8100 , the threshold values for the hourly mean wind speed were set to $5 \mathrm{~m} / \mathrm{s}$ and $15 \mathrm{~m} / \mathrm{s}$ for wind comfort and wind danger respectively. In addition, the quality classes from $\mathrm{A}$ to $\mathrm{E}$ were presented in accordance with the range of the probability of exceedance [14].

Thus, evaluation criteria are required to solve the pedestrian discomfort problems. In this regard, the evaluation of the pedestrian wind comfort conditions consists of the threshold wind velocity and the probability of exceedance.[14]

The threshold wind velocity indicates the standard of wind felt by pedestrians, and the probability of exceedance states the probability that exceeds the threshold wind velocity. There are several criteria for pedestrian wind comfort. The criteria by Lawson was shown to be most restrictive. ${ }^{[14]}$ So, the Lawson criterion will be used in the present study to propose the suitable pedestrian conditions. In this criterion, the threshold wind speed was divided into three categories based on pedestrian activities as shown in (Table 1). This criterion sets a limit of 2 percent of exceedance probabilities for every activity. 
Mohamed Hssan Hassan Abdelhafez, The degree of urban patterns compactness as a passive ...

Table 1.

The criteria and categories of Lawson criterion

\begin{tabular}{|c|c|c|}
\hline Wind Speed Threshold & $\begin{array}{c}\text { Maximum Allowed Exceedance } \\
\text { Probabilities }\end{array}$ & Description of Activity \\
\hline $1.8 \mathrm{~m} / \mathrm{s}$ & $2 \%$ & long time outdoor sitting \\
\hline $3.6 \mathrm{~m} / \mathrm{s}$ & $2 \%$ & $\begin{array}{c}\text { standing or casual walking or } \\
\text { sitting short time }\end{array}$ \\
\hline $5.3 \mathrm{~m} / \mathrm{s}$ & $2 \%$ & strolling \\
\hline
\end{tabular}

\section{Ambient conditions}

\subsection{Climatic conditions}

Aswan city is located at $24.1^{\circ}$ North latitude and $32.9^{\circ}$ East longitude, on the south of Nile Valley and surrounded by eastern and western deserts [15].The average annual temperature is $26.8{ }^{\circ} \mathrm{C}$, and about $1 \mathrm{~mm}$ of precipitation falls annually [16]. Based on 30 years of WMO Station no. 624140, the region is classified as a hot desert climate, characterized bythe harsh conditions of unbearably hot dry periods in summer, but passive cooling is possible [17]. In such climate, the air temperature exceeds the thermal comfort through the overheated period during day and night.

\subsection{The case study}

The climate played a significant role in the urban fabric of the vernacular Nubian architecture where appropriate spatial layout, in which Nubian residential clusters are arranged in organic (non-grid) and compact layout as shown in (Fig. 6), thus provides shade, prevent winds during winter, and speed up the air velocity during the summer. Also, narrow roads help to preserve the cold air for a long time; this condition contradicted to grid layouts [18]. Also, the interior spaces around the courtyards were settled. These ideas were implemented to reduce the surfaces exposed to the solar radiation, increase the amount of shadow and to achieve the most significant degree of climate compatibility at the level of theurban fabric [19].
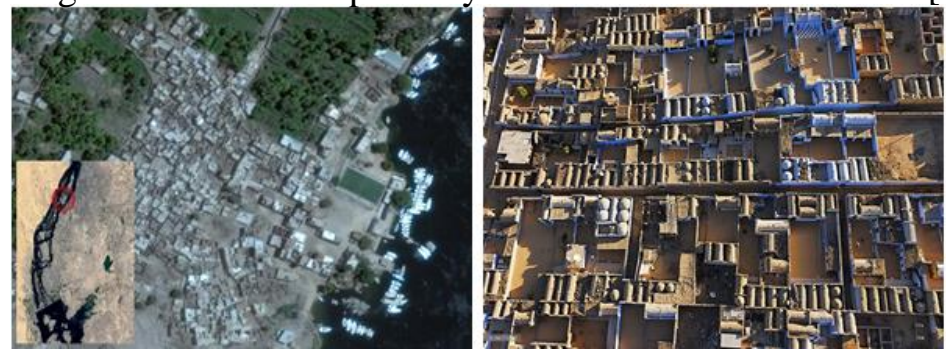

Fig. 6. Satellite image of the vernacular Nubian sites

In contrast, to save as much construction material as possible and use less of the land allocated for housing in WadiKarkar villages, the project consists of eightvillages separated from each other by the main roads which reach 24 meters width. The villages contain more than 2000 houses, these houses arranged in straight and parallel rows, separated by the secondary roads from 10 to 16 meters width [20]. The houses were organized in straight rows back-to-back. The streets were oriented North-South to allow the rows of rooms to be oriented North. By using this system, half of the houses were exposed to the North while the other half were oriented to the South. Two models were used; the first one consists of six adjacent units, while the other one consists of four adjacent units as shown in (Fig. 7). 


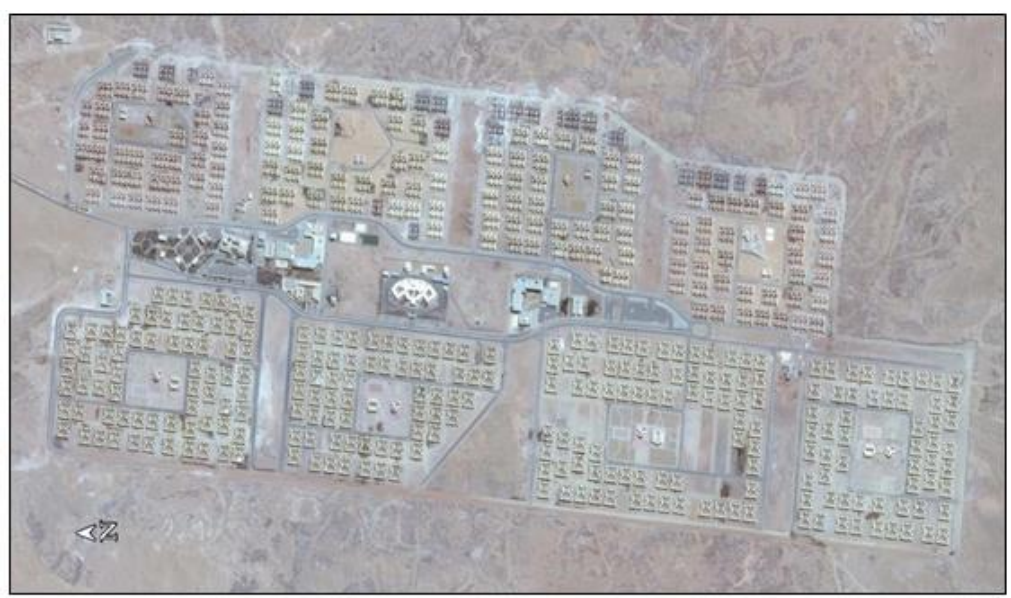

Fig. 7. Satellite image of the master plan of WadiKarkar villages

\section{Field measurements for the current situation}

To clarify the effect of vernacular design (especially the compactness degree) on the thermal conditions, the field measurements were performed at two different Nubian sites in Aswan. The first site in Gharb Aswan village which consider one of the typicalexamples for vernacular Nubian villages. The other site in one of the modern Nubian villages in WadiKarkar. The measurements indicate the indoor and outdoor air temperature through 10 hours during the period from 9:00 am to 18:00 pm for 1 - 15 August.

The comparison between the two sites as shown in (Fig. 8) indicates that the outdoor air temperature in Gharb Aswan village recorded the peak value at 12:00, where outdoor spaces exposed to the vertical solar radiation, and then the temperature decreases gradually with increasing the area of shadows. While in WadiKarkar village the temperature increased over the time, because of increasing the exposure area to the solar radiation due to the wide outdoor spaces.
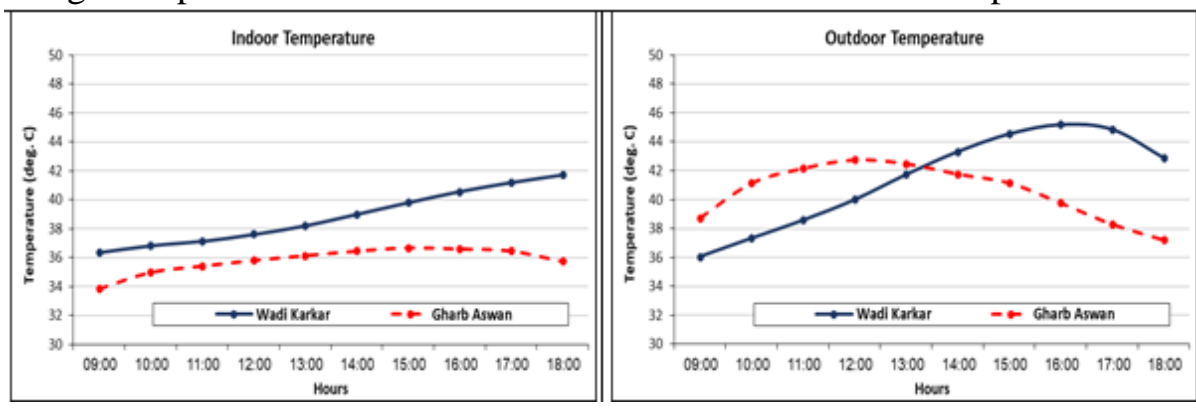

Fig. 8. The field measurements results

The effect of the outdoor spaces status on the indoor air temperature can also be observed, where the indoor air temperature in Gharb Aswan village is less than the values recorded in WadiKarkar village.

\section{Experimental validation of Autodesk CFD 2016 under the climate of Aswan city}

To consolidate the results and achieve the best accuracy, the experimental validation for the simulation program carried out by comparing the simulation results with field measurements. This validation carried out for the outdoor temperature in the climatic conditions of Aswan City. The days of June $21^{\text {st }}$, July $21^{\text {st }}$ and August $21^{\text {st }}$ were selected for the experiment. The 
Mohamed Hssan Hassan Abdelhafez, The degree of urban patterns compactness as a passive ...

measurements and the simulation were taken out along 8 hours, from 11:00 am to 18:00 pm. The results obtained from the field measurements and the simulation program represented in (Fig. 9).
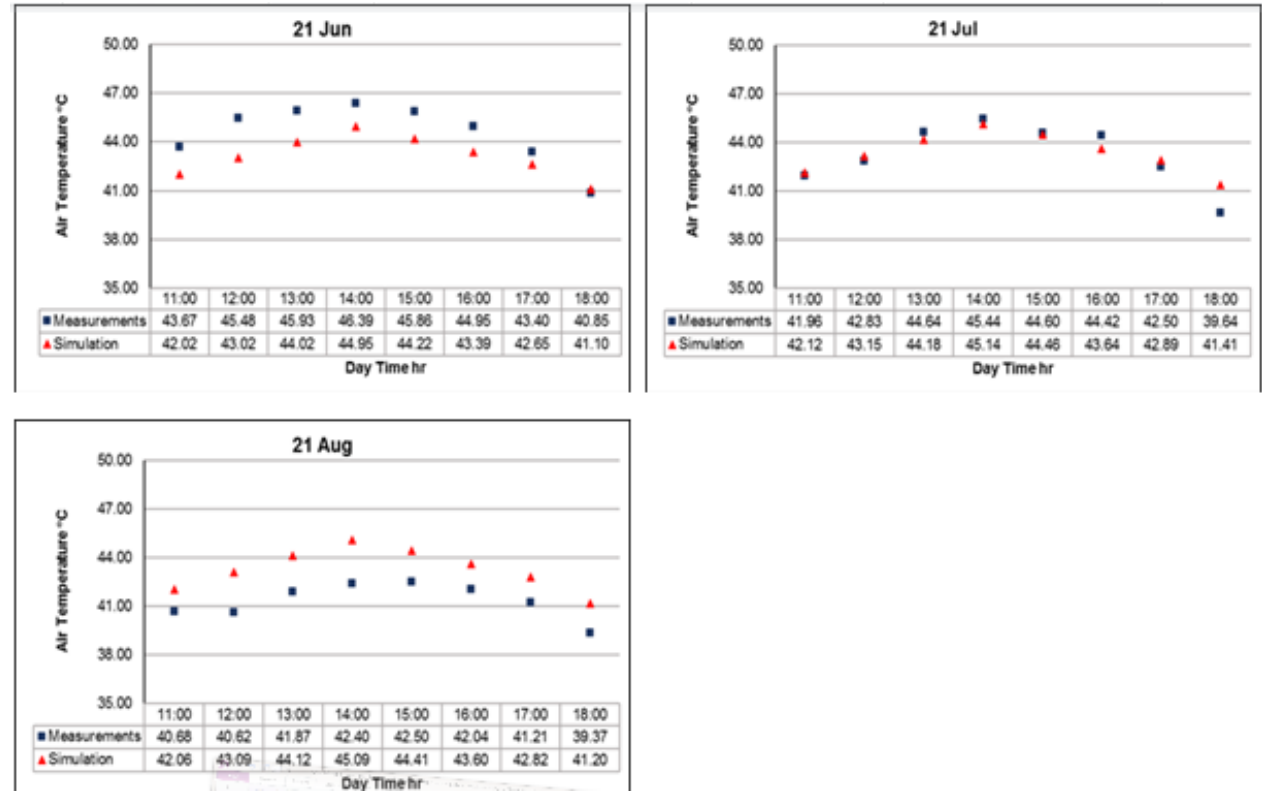

Fig. 9. The temperature difference between field measurements and simulation results

It is evident to see that the difference does not exceed $2.5^{\circ} \mathrm{C}$ (error ratio 5.4\%) in June and August, moreover, the results are very close in July.Also, the correlation coefficient was calculated for each day separately, which record $0.93,0.97$ and 0.94 respectively.

The results are very convergent between the simulation and the measurements in the three experimental days. It is an axiomatically to note a difference between the measurements and the simulation results, but it can be due to the difference between some elements used in the simulation and its peers in nature, such as color and texture of the surfaces.

\section{Results and discussion}

The simulation procedures were carried out by preparing the model for the simulation and mean radiant temperature (MRT) in six different points for each case averaged at 1.5 $\mathrm{m}$ above ground level for 4 hours to represent the outdoor thermal performance through the simulation model on the $1^{\text {st }}$ of August as an extreme summer hot day in Aswan.Mean radiant temperature (MRT) was chosen because it indicates how human beings experience radiation in their surrounding environment. If taken outdoors, MRT depends on the temperature of the sky, ground, vegetation and surrounding buildings [21]. So, MRT is more reliability to represent the outdoor thermal sensation.

\subsection{The outdoor air temperature}

As shown in (Fig. 10), the results in the North-Southorientation indicate that the temperature dropped in the case of $1: 1.5$ ratio, then the temperature increased slightly with the higher ratios. Whereas the air velocity records the peak value in the case of $1: 1.5$ ratio and decreased towards the higher ratios. 

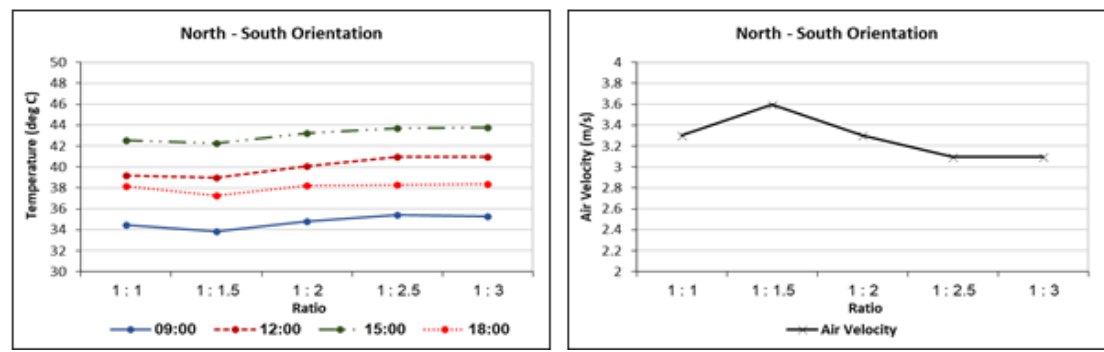

Fig. 10. The temperature and air velocity in a North-South orientation

In the East-West orientation, the temperature decreases as the ratio increases. Otherwise, the air velocity increases progressively as shown in (Fig. 11).

While in Northeast-Southwest, and Northwest-Southeastorientations the temperatures are almost constant in the simulated hours with some variation in wind speed as shown in (Fig. 12) and (Fig. 13).
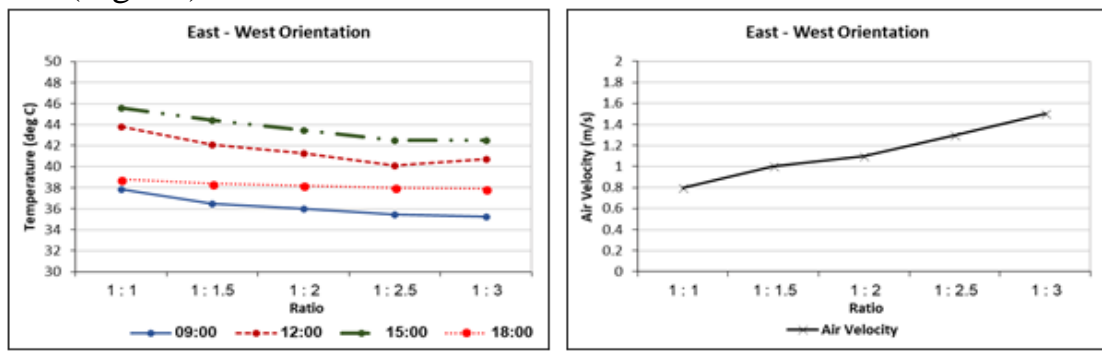

Fig. 11. The temperature and air velocity in an East-West orientation
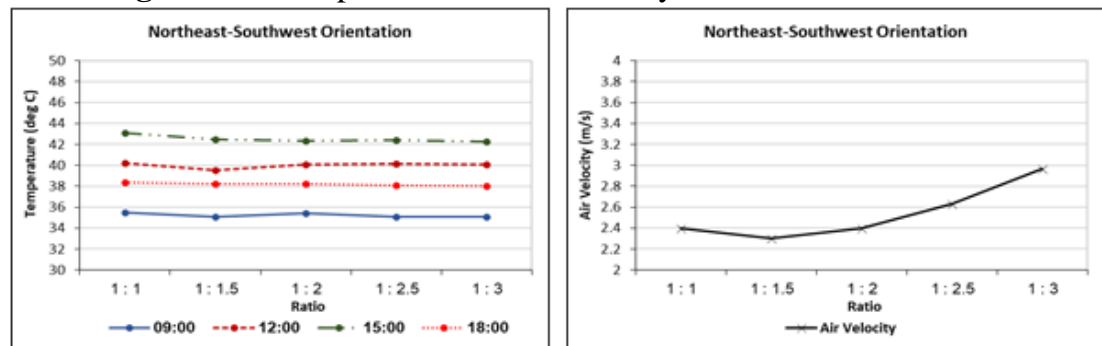

Fig. 12. The temperature and air velocity in a Northeast-Southwest orientation
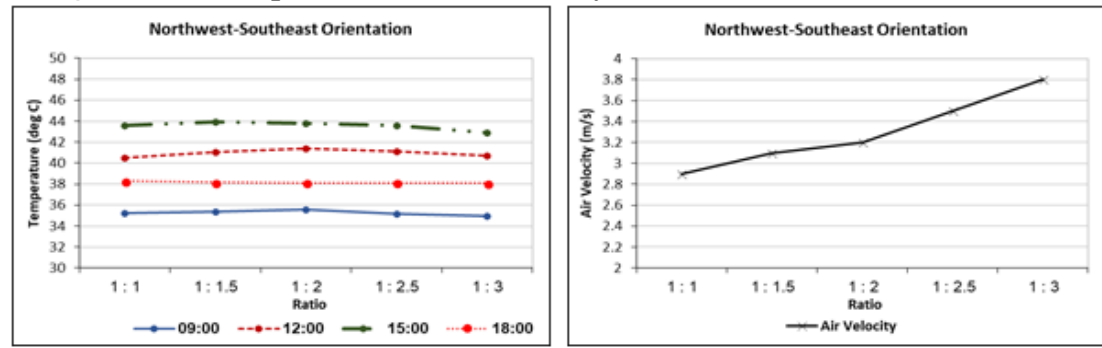

Fig. 13. The temperature and air velocity in a Northwest-Southeast orientation

Table 2 summarizes the results of temperature and air velocity in all studied cases, where the following results can be reached:

- Air temperature decreases in the hour 9:00 as well as hour 18:00 where the area of shadows increases significantly. 
Mohamed Hssan Hassan Abdelhafez, The degree of urban patterns compactness as a passive ...

- The air velocity significantly increases in North-South and Northwest-Southeast orientations as well, which is consistent with prevailing wind directions in Egypt.

- The temperature in the east-west orientation is higher than the other orientations, with a much lower air velocity, which indicates the effect of air velocity on the air temperature.

- The temperature in the ratio $1: 1.5$ decreases with the North-South orientation, achieving the best values.

- It is known that the air velocity increases at the top of high buildings, due to the friction factor near the surface of the earth, which slows down the flow of the air. In addition, the low pressure behind the high buildings causes an opposite air flow, and this flow increase as the height of the building facing the wind increasing, this explains the decreasing of the air velocity in a Northeast-Southwest orientation, specifically in the $1: 1.5$ ratio, then the air velocity return to rising again in the higher ratios.

\section{Table 2.}

The summarized results of temperature and air velocity in all studied cases

\begin{tabular}{|c|c|c|c|c|c|c|c|}
\hline & \multicolumn{5}{|c|}{ The ratio of street width to buildings height } \\
\hline & & & $1: 1$ & $1: 1.5$ & $1: 2$ & $1: 2.5$ & $1: 3$ \\
\hline \multirow{5}{*}{ 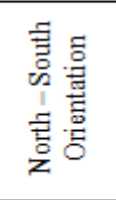 } & \multirow{4}{*}{ 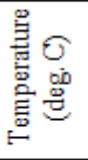 } & 9:00 & 34.4 & 33.9 & 34.8 & 35.4 & 35.3 \\
\hline & & $12: 00$ & 39.2 & 39.0 & 40.1 & 41.0 & 41.0 \\
\hline & & $15: 00$ & 42.6 & 42.2 & 43.3 & 43.7 & 43.8 \\
\hline & & $18: 00$ & 38.2 & 37.3 & 38.2 & 38.3 & 38.4 \\
\hline & \multicolumn{2}{|c|}{ Air velocity $(\mathrm{m} / \mathrm{s})$} & 3.3 & 3.6 & 3.3 & 3.1 & 3.1 \\
\hline \multirow{5}{*}{ 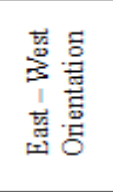 } & \multirow{4}{*}{ 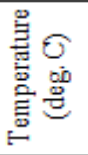 } & 9:00 & 37.9 & 36.5 & 36.0 & 35.5 & 35.3 \\
\hline & & $12: 00$ & 43.8 & 42.1 & 41.3 & 40.1 & 40.7 \\
\hline & & $15: 00$ & 45.6 & 44.4 & 43.5 & 42.5 & 42.5 \\
\hline & & $18: 00$ & 38.8 & 38.4 & 38.2 & 38.0 & 37.9 \\
\hline & \multicolumn{2}{|c|}{ Air velocity $(\mathrm{m} / \mathrm{s})$} & 0.8 & 1.0 & 1.1 & 1.3 & 1.5 \\
\hline \multirow{5}{*}{ 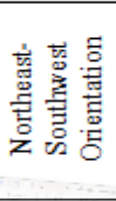 } & \multirow{4}{*}{ 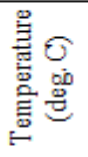 } & 9:00 & 35.5 & 35.1 & 35.4 & 35.1 & 35.1 \\
\hline & & $12: 00$ & 40.2 & 39.5 & 40.1 & 40.1 & 40.1 \\
\hline & & $15: 00$ & 43.1 & 42.5 & 42.4 & 42.4 & 42.3 \\
\hline & & $18: 00$ & 38.4 & 38.2 & 38.2 & 38.1 & 38.0 \\
\hline & \multicolumn{2}{|c|}{ Air velocity $(\mathrm{m} / \mathrm{s})$} & 2.4 & 2.3 & 2.4 & 2.6 & 2.9 \\
\hline \multirow{5}{*}{ 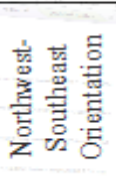 } & \multirow{4}{*}{ 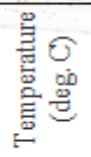 } & $9: 00$ & 35.2 & 35.4 & 35.6 & 35.2 & 35.0 \\
\hline & & $12: 00$ & 40.5 & 41.0 & 41.4 & 41.1 & 40.7 \\
\hline & & $15: 00$ & 43.6 & 43.9 & 43.8 & 43.6 & 42.9 \\
\hline & & $18: 00$ & 38.3 & 38.2 & 38.1 & 38.1 & 38.1 \\
\hline & \multicolumn{2}{|c|}{ Air velocity $(\mathrm{m} / \mathrm{s})$} & 2.9 & 3.1 & 3.2 & 3.5 & 3.8 \\
\hline
\end{tabular}

\subsection{The relationship between the pattern compactness degree, air temperature, and air velocity}

In order to find the relationship between the compactness degree, air temperature, and air velocity, the correlation coefficient ${ }^{*}$ obtained in all cases, taking into consideration that the sample is a small size sample due to investigate only five ratios and only four hours.

\footnotetext{
* Correlation coefficient is a statistical measure of the strength of a linear relationship between paired data.Furthermore: (Source: http://www.statstutor.ac.uk/resources/uploaded/pearsons.pdf).

- Positive values denote positive linear correlation.

- Negative values denote negative linear correlation.

- A value of 0 denotes no linear correlation.

- The closer the value is to 1 or -1 , the stronger the linear correlation.
} 
Table (3) shows the existence of a negative correlation in all cases except two cases at 12:00 in Northeast-Southwest and Northwest-Southeast orientations, where the correlation is positive. This means that the higher the air velocity the lower the air temperature and vice versa. It can be also observed increasing the correlation in North-South, and East-West orientations.

The least possible correlation occurs at 12:00 noon, this may be due to the intensity of direct vertical solar radiation at this hour of the day.

Table 3.

The results of the correlation coefficient in all studied cases

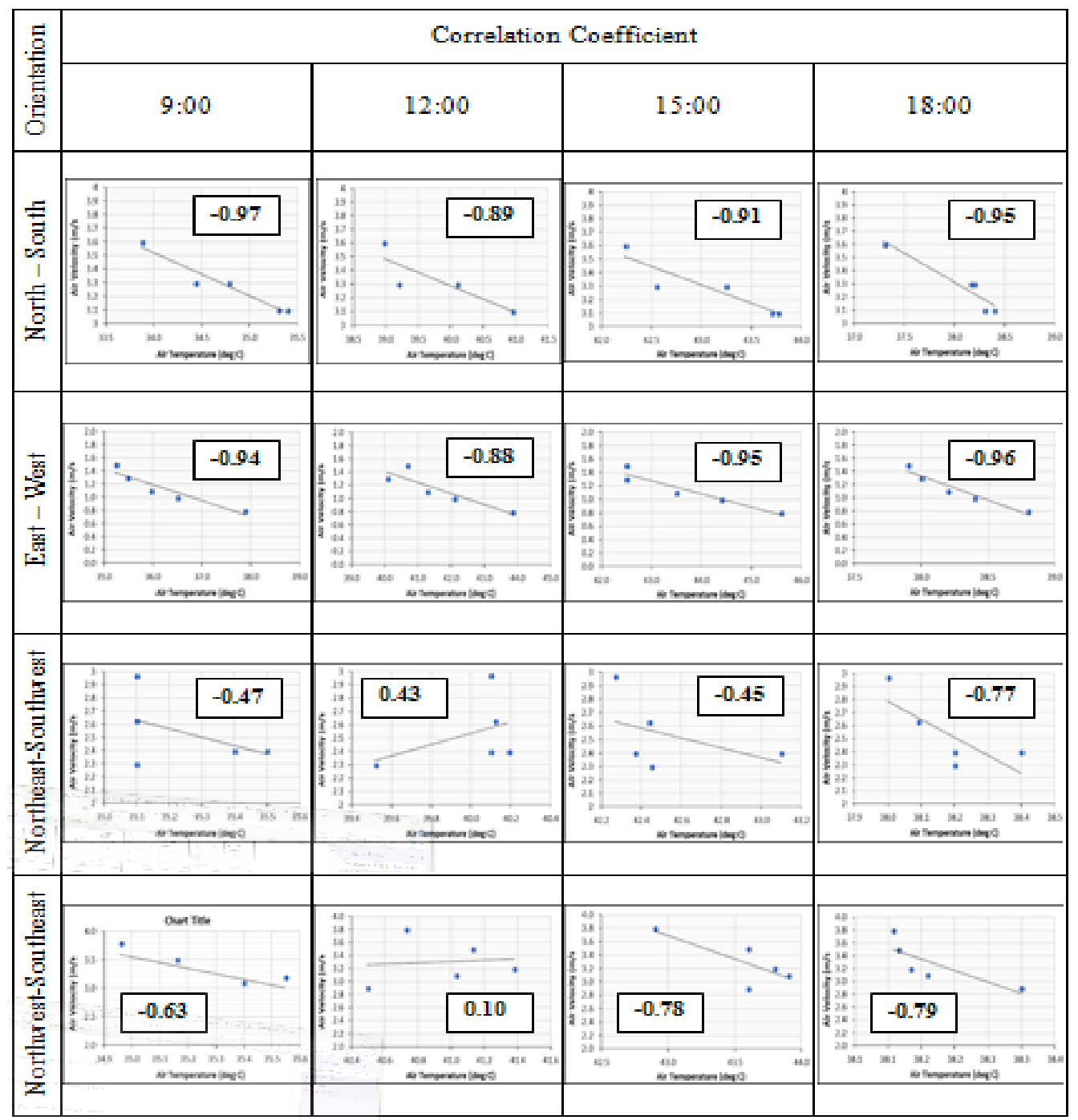

\subsection{Pedestrian wind comfort}

There is a mutual relationship between Nubian culture and architectural output, where the Nubian houses had a special character according to customs, traditions, and cultures. One of the influences of culture on Nubian architecture, the presence of terraces (Mastaba in Arabic) in the courtyard, and in front of the entrances (as shown in Fig.14) to receive 
Mohamed Hssan Hassan Abdelhafez, The degree of urban patterns compactness as a passive ...

guests and sit outside to talk and frolic [22]. From this standing point, the importance of pedestrians' wind comfort settled, so, based on this perspective, this study used the Lawson criterion to evaluate the wind comfort conditions in all cases, so as to suggest the suitable condition according to the compactness degree and the orientation.
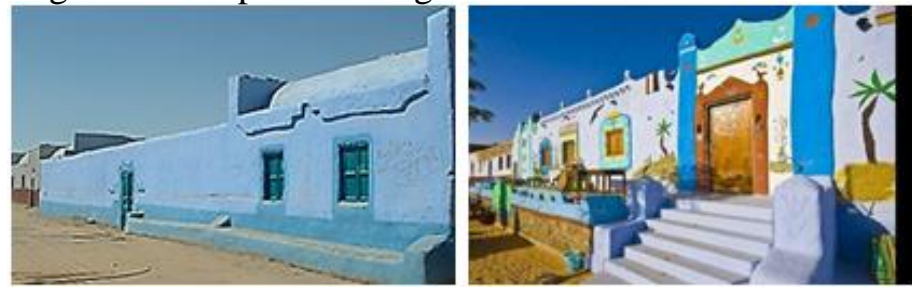

Fig. 14. Using the Mastaba in front of the entrances

By comparing the air velocity results obtained from the simulation with air velocity limits used in the Lawson criterion, it can be argued that the air velocity is suitable for long time outdoor sitting in North-South, Northeast-Southwest, and Northwest-Southeast orientations, but in East-West orientation the air velocity does not reach the lower limit of the long time outdoor sitting category.

In Northwest-Southeast orientation, the air velocity exceeds the threshold of the second category (standing or casual walking or sitting short time) in the ratio of $1: 3$.

\section{Conclusion}

There is a significant effect of urban compact pattern, where the outdoor thermal and wind comfort is a trade-off between different design factors, which varies according to the climatic design of outdoor spaces. Where the area of shadows increases and air movement is affected, all of this varies according to the orientation.

According to the field measurements, the difference between the vernacular Nubian architecture and the modern one in WadiKarkar has clearly emerged, where the temperature decreased either outdoor or indoor in the vernacular village of Gharb Aswan than its counterpart in the modern village of WadiKarkar. The ratio $1: 1.5$ in the NorthSouth orientation records the best value both at the temperature and the air velocity appropriate for various life activities, therefore, this ratio should be applied considering appropriate orientation.It is also necessary to choose the appropriate orientation for the streets, according to the prevailing wind movement in Egypt.

On the other hand, there is a negative correlation in all cases which means that the higher the air velocity the lower the air temperature and vice versa, hence the air movement should be considered as an effective factor in the temperature of the outdoor spaces. The intensity of direct vertical solar radiation at 12:00 noon is the most influential factor on the air temperature. The air velocity in most of the cases is suitable for long time outdoor sitting in different orientations.

It is essential to work on the integration between the building and the external surrounding spaces; the results prove the vitality of using the compact pattern as an adaptation strategy on the scale of urban development in Egypt. This vitality is not only for the newly constructed developments but also for the already existing ones and gives an impression about how can invest in our built environment. 


\section{REFERENCES}

[1]Mohamad Fahmy: "Interactive urban form design of local climate scale in hot semi-arid zone", Ph.D. Thesis, School of Architecture, University of Sheffield, Sheffield, UK, 2010.

[2]Mohamad Fahmy, Stephen Sharples: "Passive design for urban thermal comfort: a comparison between different urban forms in Cairo, Egypt", PLEA 2008 - 25th Conference on Passive and Low Energy Architecture, Dublin,Ireland, 2008.

[3]Reid Ewing, et al.: "Growing Cooler: The Evidence on Urban Development and Climate Change", Urban Land Institute, USA, 2007.

[4]Fazia A. Toudert: "Dependence of Outdoor Thermal Comfort on Street Design in Hot and Dry Climate", Ph.D. Thesis, Institute of Meteorology, Freiburg, Germany, 2005.

[5]MarwaM. M. Rashwan:"Architecture System \& Nubian Repertoire as an Approach to Teaching the Multi-Surface Designs", M.Sc. thesis, University of Helwan, Cairo, Egypt, 2012.

[6]Yasser O. M. Mahgoub: "The Nubian experience: A study of the social and cultural meanings of architecture", Ph.D. Thesis, University of Michigan, USA, 1990.

[7]Hamada S. Abd Elkader: "Assessment thermal performance of the Nubian house - A comparison study between traditional and modern houses", M.Sc. thesis, University of Aswan, Aswan, Egypt, 2017.

[8]Tarek M. Saad: "The Egyptian Village: A study of the design and construction patterns in the heritage and modern Nubian communities", M.Sc. thesis, University of Alexandria, Alexandria, Egypt, 1987.

[9]Central Authority for Reconstruction and Housing, Southern Upper Egypt Reconstruction Authority: "Project of rehabilitation and resettlement of Nubians in WadiKarkar region", Authority Brochure 2012.

[10]Hamada S. Abd Elkader, Mohamed H. Hassan, Abdelmonteleb M. Ali: "Thermal Performance of Traditional and Modern Nubian House - Comparative Study", Journal of Engineering Sciences, Faculty of Engineering, Assiut University, Vol. 45, Issue 4, 2017.

[11]MarcelBottema: "A method for optimization of wind discomfort criteria", Journal of Building and Environment, Vol. 35, Issue 1, 2000.

[12] TharakaGunawardena, Shiromal Fernando, PriyanMendis, BhathiyaWaduge, DilinaHettiarachchi: "Wind analysis and design of tall buildings, the state of the art", International Conference on Structural Engineering and Construction Management (ICSECM), Kandy, Sri Lanka,2017.

[13] Ted Stathopoulos: "Wind and Comfort", $5^{\text {th }}$ European \& African Conference on Wind Engineering (EACWE 5), Florence, Italy, 2009.

[14]Hyungkeun Kim, Kyungsoo Lee and Taeyeon Kim: "Investigation of Pedestrian Comfort with Wind Chill during Winter", Journal of Sustainability, Vol. 10, Issue 1, 2018.

[15]Mohamed H. H. Abdelhafez: "Development of Building Simulation Model for Passive Cooling in Hot Desert Climate", Ph.D. Thesis, Faculty of Engineering, South Valley University, Aswan, Egypt, 2010.

[16]Darrel Hess, Dennis G. Tasa: "McKnight's Physical Geography: A Landscape Appreciation", Prentice Hall, 2011.

[17]Mohammad Fahmy, Hany Mokhtar, and Amr Gira: "Adaptive urban form design on a climate change basis - A case study in Nubia, Egypt", ICUC8 - 8th International Conference on Urban Climates, Dublin, Ireland, 2012.

[18]Ola A. M. Bayoumi: "Nubian Vernacular architecture \& contemporary Aswan buildings' enhancement", Alexandria Engineering Journal, 2017, http://dx.doi.org/10.1016/j.aej.2016.01.002

[19]Ahmed M. Hamada: "The vernacular architecture and environmental compatibility: Abulreesh village in Aswan as a case study", M.Sc. thesis, Assiut University, Assiut, Egypt, 2004.

[20] Tarek Rakha, PouyaZhand and Christoph Reinhart: "A Framework for Outdoor Mean Radiant Temperature Simulation: Towards Spatially Resolved Thermal Comfort Mapping in Urban Spaces", The 15th IBPSA Conference, San Francisco, USA, 2017. 
Mohamed Hssan Hassan Abdelhafez, The degree of urban patterns compactness as a passive ...

\section{درجة اندماج الأنماط الحضرية كاستراتيجية تبريد سلبية في المناخ الصحراوي الصار الصار

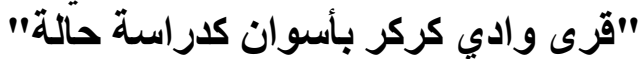

الملخص

ترتبط الر احة الحرارية للمشاة بالأنماط الحضرية الناتجة من منهجياتالتخطيط الحضري المحددة، وتجدر

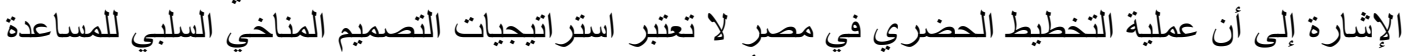

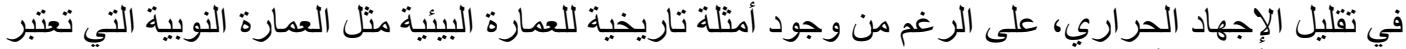

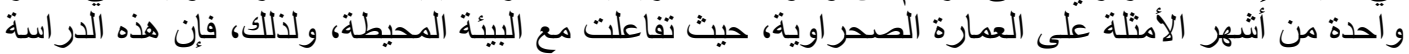

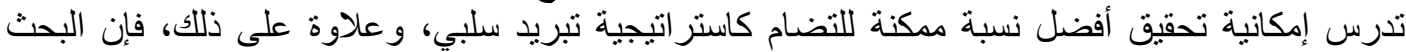

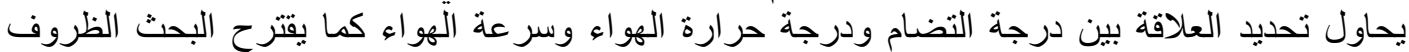

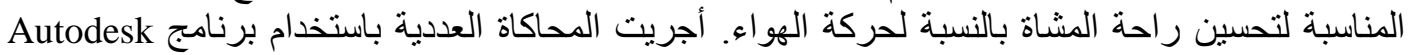

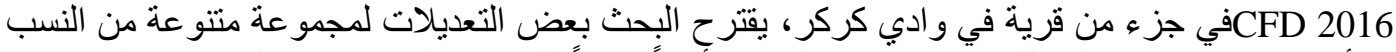

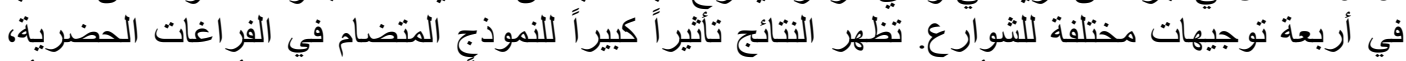

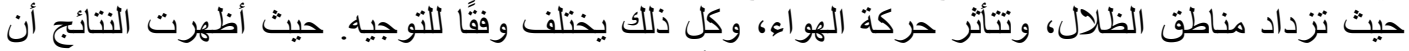

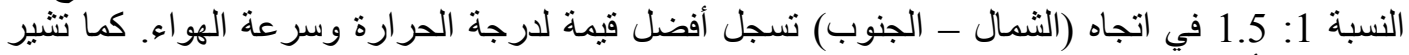

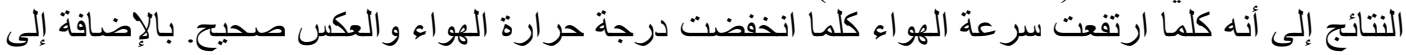
ذللك، فإن سرعة الهو اء في معظم الحالات مناسبة للجلوس لفترة طويلة في الهواء الطلق في عدة نوجيهاء التهات مختلفة. 